\title{
Intervention with the aldose reductase inhibitor, tolrestat, in renal and retinal lesions of streptozotocin-diabetic rats
}

\author{
M.L.McCaleb ${ }^{1}$, M.L.McKean ${ }^{1}$, T.C.Hohman ${ }^{1}$, N.Laver ${ }^{2}$ and W. G. Robison Jr. ${ }^{2}$ \\ 1 Wyeth-Ayerst Research, Princeton, New Jersey and the ${ }^{2}$ National Eye Institute, National Institute of Health, Bethesda, Maryland, USA
}

\begin{abstract}
Summary. The progressive increase in urinary albumin excretion, which precedes the development of diabetic nephropathy, can be prevented in diabetic rats if the aldose reductase inhibitor, tolrestat, is administered at the initiation and throughout the duration of hyperglycaemia. We therefore determined the ability of tolrestat to intervene in the further progression of already established urinary albumin excretion of streptozotocin-diabetic female Wistar rats. Two months after streptozotocin injection, diabetic rats were grouped as low-urinary albumin excretion $(0.2-1.0 \mathrm{mg}$ albumin/day) or high-urinary albumin excretion (1.9-5.9 $\mathrm{mg}$ albumin/day), at which time tolrestat intervention $(25 \mathrm{mg} / \mathrm{kg}$ per day) was begun for half of the diabetic rats in each urinary albumin excretion group. After six months of treatment tolrestat caused
\end{abstract}

a significant reduction in the urinary albumin excretion rate of the low-urinary albumin excretion group only. The diabetes-induced rise of total urinary protein in both groups was significantly reduced by tolrestat. Furthermore, the diabetes-induced increase $(49 \%)$ in the thickness of the basement membranes of retinal capillaries from the outer plexiform layer was significantly diminished by tolrestat administration. In conclusion, intervention therapy with the aldose reductase inhibitor, tolrestat, can reduce the progression of urinary albumin excretion and retinal basement membrane thickening in long-term diabetic rats.

Key words: Nephropathy, retinopathy, diabetic complications, aldose reductase.
The long-term hyperglycaemia associated with both Type 1 (insulin-dependent) and Type 2 (non-insulindependent) diabetes mellitus results in the slow development of multiple secondary complications. Diabetic nephropathy, one of the three major long-term complications, occurs in $30-40 \%$ of the diabetic population [1]. The early stages of diabetic nephropathy are characterized by an elevation of urinary albumin excretion (UAE) [2]. The albuminuria progresses to overt proteinuria, finally resulting in end-stage renal failure in diabetic patients. In confirmation of previous studies $[3,4]$, we found that six months of streptozotocin-induced diabetes in rats caused a substantial increase in the UAE. Furthermore, treatment of the diabetic rats with the aldose reductase inhibitor, tolrestat, for the entire duration of the 6-month experiment prevented the development of albuminuria [5].

A second major long-term complication of diabetes, retinopathy, is one of the leading causes of blindness [6]. Thickening of basement membranes occurs in the vessels of several tissues of diabetic patients and has been considered to be a hallmark of diabetes [7-9]. The capillary basement membranes of the retina normally increase in thickness with age $[10]$; this process is accelerated by diabetes $[7$,
$8,11]$. Treatment of galactosaemic or BB diabetic rats with aldose reductase inhibitors prevents the diabetes-like thickening of capillary basement membranes [12-14].

The above studies suggest the potential usefulness of aldose reductase inhibitors in preventing the progression of diabetic nephropathy and retinopathy. Previously it has been demonstrated that vigilant control of hyperglycaemia by insulin treatment in diabetic patients and rats can reverse the progressive elevation of established albuminuria [15-17]. For this reason it was important to assess the effects of intervention therapy with the aldose reductase inhibitor, tolrestat, on albuminuria and retinal capillary basement membrane thickening in streptozotocindiabetic rats.

\section{Materials and methods}

\section{Animal treatments}

Female Wistar rats (Charles River Breeding Laboratories; $200 \mathrm{~g}$ and 10 weeks of age at the beginning of the study) were used. Streptozotocin (STZ) $(45 \mathrm{mg} / \mathrm{kg}$ ) was injected into the tail vein of 369 rats and 
a vehicle $(0.03 \mathrm{mmol} / \mathrm{l}$ citrate, $\mathrm{pH} 4.5)$ was administered to 22 rats. Two months after the administration of STZ, 122 of the 306 surviving diabetic rats were separated into two sets, based on their urinary albumin levels (low UAE, $n=46$; high UAE, $n=76$ ). The diabetic rats having low ( $<0.9 \mathrm{mg} /$ day) (Groups 2 and 3 ) or high (2.0$6.0 \mathrm{mg} /$ day) (Groups 4 and 5) levels of UAE were then randomly assigned to a drug (tolrestat)- or non-drug-treated group. The remaining 184 diabetic rats were eliminated from the study for one or more of the following reasons: 1 ) the UAE level at month 2 was either between 0.9 to $2.0 \mathrm{mg} /$ day or $>6.0 \mathrm{mg} / \mathrm{day} ; 2$ ) the plasma glucose level of an STZ-injected rat was either $<16.8$ or $>44.8 \mathrm{mmol} / \mathrm{l} ; 3$ ) the urine volume of an STZ-injected rat was $<100 \mathrm{ml} /$ day, or there was a substanial $(>20 \mathrm{~g}$ ) loss of body weight during month 2 , and therefore the general health of the animal was probably not adequate to survive the remaining 6 months of the experiment.

At monthly intervals (months 0 and 1-8), the rats were placed individually into metabolism cages (Nalgene Co.; Rochester, N. Y., USA) (ad libitum food and $150 \mathrm{ml}$ water) for $24 \mathrm{~h}$ collection of urine. Total volume of urine was recorded, aliquots of urine were centrifuged $(100 \times \mathrm{g}, 10 \mathrm{~min})$ to remove particulate matter, and multiple aliquots were frozen at $-70^{\circ} \mathrm{C}$. The concentration of tolrestat admixed to the ground chow (3.5-4.0 g tolrestat per $25 \mathrm{~kg}$ chow) was adjusted weekly to provide an average daily dose of $25 \mathrm{mg} / \mathrm{kg}$, based on the mean body weight and food consumption of the drug-treated rats. This dose of tolrestat was used since it had been shown previously in rats to prevent diabetes-induced albuminuria and renal accumulation of sorbitol [5]. Since we have demonstrated previously that tolrestat treatment (6 months) does not alter UAE levels in non-diabetic rats [5], a tolrestat-treated nondiabetic control group was not included. All animals were given free access to water and food and were maintained under a $12 \mathrm{~h}$ on/off light cycle with cage-level illuminations of 15 to 30 foot candles. Animal care and treatment conformed to the NIH Guide for the Care and Use of Laboratory Animals. After 8 months of diabetes, the surviving rats were anaesthetized, kidneys perfused with $154 \mathrm{mmol} / 1 \mathrm{NaCl}$, renal cortex and inner medulla were separated and rapidly frozen.

\section{Electron microscopy}

Eyes from a random sample of rats from each group were fixed by immersion for $24 \mathrm{~h}$ or more at room temperature in a solution of $2.5 \%$ glutaraldehyde and $6 \%$ sucrose, buffered to $\mathrm{pH} 7.2$ with $50 \mathrm{mmol} / \mathrm{l}$ sodium cacodylate. Small portions $\left(<1.0 \mathrm{~mm}^{2}\right)$ of retina were taken from within $1.5 \mathrm{~mm}$ of the optic disk of the superior temporal quadrant. The specimens were post-fixed in $\mathrm{OsO}_{4}$ buffered with $150 \mathrm{mmol} / \mathrm{l} \mathrm{Na-K}$ phosphate ( $\mathrm{pH} 7.4$ ), embedded, sectioned, stained and examined using a JEM $100 \mathrm{~B}$ electron microscope (JEOL USA Inc.; Peabody, Mass., USA). Micrographs of capillaries of the outer plexiform layer were taken at a magnification of $x 5,000$. Only those capillaries which were transected in a perpendicular or near-perpendicular direction and showed unambiguous basement membrane borders were selected for analysis. Quantification of basement membrane thickness was performed using a Bioquant II digitizing morphometric system ( $R$ \& M Biometrics; Nashville, Tenn., USA) [18]. The mean areas for all basement membranes of the retinal capillaries, including those enveloping the pericytes, were determined and the mean values were divided by the total length of the basement membranes [12]. The measurements were expressed as mean basement membrane thickness in nanometers. The procedures were carried out under masked conditions with 20 micrographs of capillaries from each of either six age-matched nondiabetic control rats or 12 diabetic rats randomly selected from each experimental group.

\section{Biochemicalmethods}

Glucose and sorbitol in tissue samples were converted to their aldonitrile acetate derivatives [19] and quantitated by capillary gas chromatography. Using a VP Analyzer (Abbott Laboratories, North Chicago, Ill., USA) aliquots of plasma were assayed for glucose, creatinine, urea nitrogen, and triglycerides, and urine samples were assayed for glucose and creatinine. Total urinary protein was determined by a microtitre plate assay using the BCA Protein Assay Reagents (Pierce, Rockford, Ill., USA). Levels of albumin in the urine from individual rats were determined by an ELISA used previously [5].

\section{Statistical analysis}

Because of the unequal variance among groups, raw data were usually log transformed prior to statistical analysis and the baseline UAE rate (i.e., mean of months 1 and 2) was subtracted from the UAE rate of months 3-8 to adjust for differences in baseline UAE. Since animal selection into treatment group at month 2 was dependent upon baseline UAE levels, statistical evaluation of drug effects was performed separately for rats of the low-UAE (Groups 2 and 3 ) and high-UAE (Groups 4 and 5) groups. The transformed data were analysed using either a repeated measures analysis of variance or a one-way analysis of variance. The least significant difference between groups was considered statistically significant if $p<0.05$.

\section{Results}

At the termination of the experiment (month 8) all of the surviving STZ-injected rats demonstrated significant polyuria, glycosuria and a lower body weight than nondiabetic rats (Table 1). Fed plasma levels of glucose and triglycerides were substantially elevated, whereas plasma

Table 1. Characteristics of animals in each group at end of experiment (month 8)

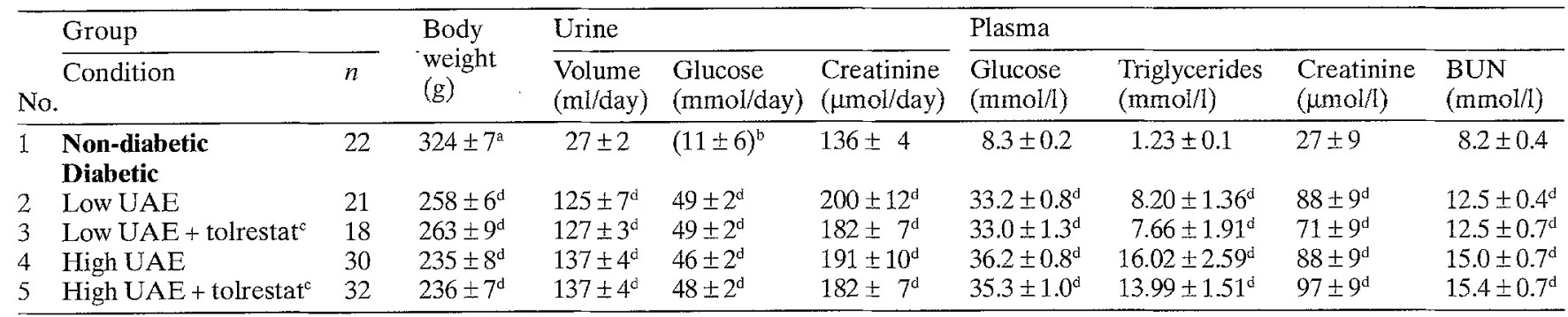

${ }^{a}$ Values are mean $\pm \mathrm{SEM}$; ${ }^{\mathrm{b}}$ Value of Group 1 is reported as $\mu \mathrm{mol} / \mathrm{day}$; ${ }^{c}$ Daily dose of $25 \mathrm{mg} / \mathrm{kg}$ admixed to the diet; ${ }^{d} p<0.05 \mathrm{vs}$ Group 1; ${ }^{e} p<0.05$ vs respective non-treated diabetic group.

$\mathrm{UAE}=$ urinary ulbumin excretion; $\mathrm{BUN}=$ blood urea nitrogen 
Table 2. Carbohydrate levels in kidney at end of experiment (month 8)

\begin{tabular}{|c|c|c|c|c|c|c|}
\hline \multirow[b]{2}{*}{ No. } & \multicolumn{2}{|l|}{ Group } & \multicolumn{2}{|c|}{ Renal cortex } & \multicolumn{2}{|c|}{ Inner renal medulla } \\
\hline & Condition & $n$ & Glucose & Sorbitol & Glucose & Sorbitol \\
\hline 1 & $\begin{array}{l}\text { Non-diabetic } \\
\text { Diabetic }\end{array}$ & 22 & $0.5 \pm 0.1^{\mathrm{a}}$ & $0.02 \pm 0.00$ & $0.3 \pm 0.0$ & $0.98 \pm 0.10$ \\
\hline 2 & Low UAE & 21 & $5.1 \pm 0.4^{\mathrm{b}}$ & $0.10 \pm 0.01^{\mathrm{b}}$ & $7.5 \pm 0.6^{\mathrm{b}}$ & $1.55 \pm 0.21^{\mathrm{b}}$ \\
\hline 3 & Low UAE + tolrestat & 18 & $5.9 \pm 0.6^{\mathrm{b}}$ & $0.05 \pm 0.01^{\mathrm{b}, \mathrm{c}}$ & $8.2 \pm 0.7^{b}$ & $0.30 \pm 0.04^{b, c}$ \\
\hline 4 & High UAE & 30 & $7.9 \pm 0.6^{b}$ & $0.13 \pm 0.01^{\mathrm{b}}$ & $7.3 \pm 0.5^{\mathrm{b}}$ & $0.71 \pm 0.06^{\mathrm{b}}$ \\
\hline 5 & High UAE + tolrestat & 32 & $7.2 \pm 0.5^{b}$ & $0.05 \pm 0.01^{\mathrm{b}, \mathrm{c}}$ & $8.8 \pm 0.7^{b}$ & $0.15 \pm 0.01^{b, c}$ \\
\hline
\end{tabular}

a Values are nmol/mg tissue, mean $\pm \mathrm{SEM} ;{ }^{\mathrm{b}} p<0.05$ vs Group $1 ;{ }^{\mathrm{c}} p<0.05$ vs respective non-treated diabetic group.

$\mathrm{UAE}=$ urinary albumin excretion

Table 3. Urinary albumin excretion (UAE) at month 2 (pre-treatment)

\begin{tabular}{|c|c|c|c|c|}
\hline \multirow[b]{2}{*}{ No. } & \multicolumn{2}{|l|}{ Group } & \multicolumn{2}{|c|}{$\mathrm{UAE}$ (mg/day) } \\
\hline & Condition & $n$ & Mean $\pm S E M$ & range \\
\hline 1 & $\begin{array}{l}\text { Non-diabetic } \\
\text { Diabetic }\end{array}$ & 22 & $0.5 \pm 0.1$ & $0.1-3.4$ \\
\hline 2 & Low UAE & 23 & $0.6 \pm 0.1$ & $0.3-1.0$ \\
\hline 3 & Low UAE + Tolrestat ${ }^{2}$ & 23 & $0.6 \pm 0.1$ & $0.2-1.0$ \\
\hline 4 & High UAE & 38 & $3.5 \pm 0.2^{\mathrm{b}}$ & $2.1-5.9$ \\
\hline 5 & High UAE + Tolrestat ${ }^{a}$ & 38 & $3.6 \pm 0.2^{b}$ & $1.9-5.9$ \\
\hline
\end{tabular}

a Tolrestat was administered during months $3-8$ only; ${ }^{\mathrm{b}} p<0.05 \mathrm{vs}$ Group 1

levels of creatinine and urea nitrogen were only slightly increased. None of the above parameters were significantly altered by tolrestat treatment. Similar plasma glucose levels were also obtained after 2 and 4 months of diabetes. In contrast, however, administration of tolrestat to the diabetic rats significantly reduced the tissue levels of sorbitol at month 8 (Table 2).

\section{Urinary protein}

Two months after the injection of STZ, the 306 diabetic rats had UAE levels ranging from 0.1 to $32.4 \mathrm{mg} /$ day. Of these diabetic rats 122 were distributed (see Methods) into Groups 2-5 such that the UAE levels of Groups 4 and 5 (high UAE), but not Groups 2 and 3 (low UAE), were significantly different from the UAE level of the nondiabetic rats at month 2 (Table 3 ).

The UAE level of all non-diabetic and diabetic rats increased throughout the 8-month experimental period (Fig. 1). During months 3-8, the diabetic rats in the high UAE groups continued to have substantially greater UAE levels than those of the low UAE groups. After 6 months of treatment, reductions of UAE by tolrestat were observed in both groups [low UAE $(-53 \%)$ and high UAE $(-36 \%)$ ] which, when adjusted for baseline levels (mean level of months 1 and 2), were significantly lower in the low UAE group only.

Unlike urinary albumin excretion, the daily excretion of total protein increased abruptly with the onset of diabetes (Fig. 2), paralleling the diabetes-induced changes in urine volume (data not shown). After 4 to 6 months of diabetes, the levels of urinary total protein of all groups began to increase gradually. The reduction in total protein excretion by tolrestat was significant at month 8 for the low UAE group and months 7 and 8 for the high UAE group.

After 8 months of hyperglycaemia, the UAE levels of non-treated diabetic rats were highly correlated with the plasma triglycerides $(r=0.70, p<0.001)$. There was a similar, but less pronounced, correlation of UAE and plasma triglyceride levels at month 8 in the diabetic rats treated with tolrestat $(r=0.45, p<0.01)$. In contrast, the plasma glucose levels of the diabetic rats were not significantly correlated with the rate of UAE $(r=0.31$ and $r=0.22, p>0.05$ for both non-treated and treated diabetic rats, respectively).
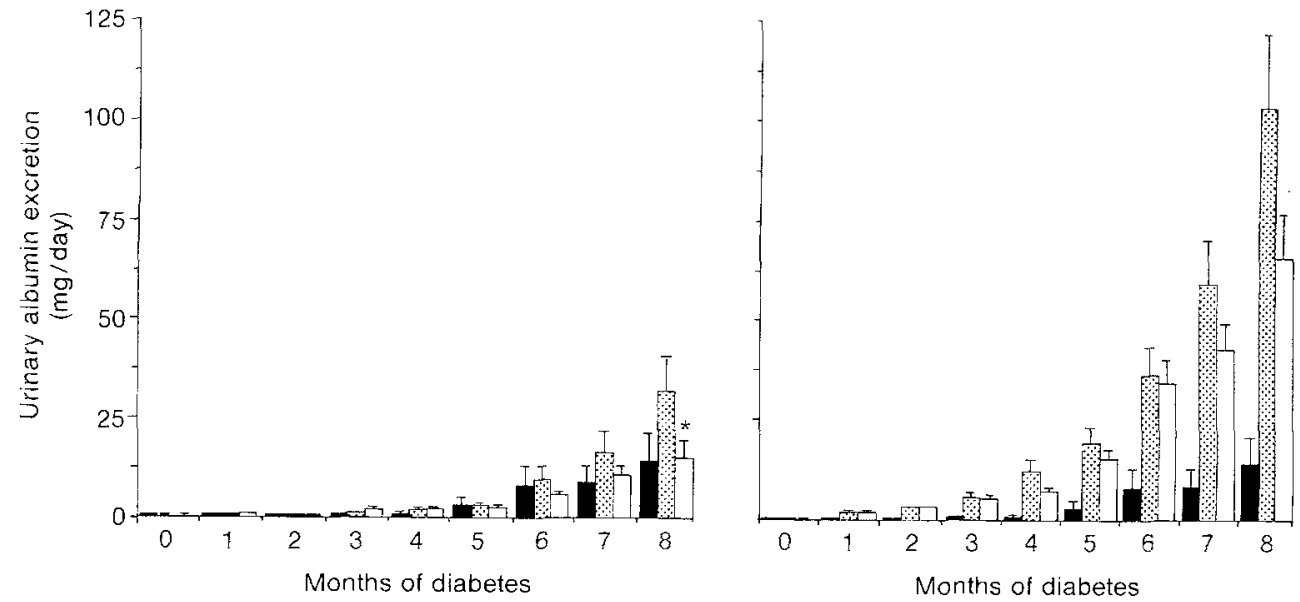

Fig. 1. Effect of intervening tolrestat treatment (months 3-8) on urinary albumin excretion (UAE) of diabetic rats in either the low-UAE (left) or high-UAE (right) groups. * $p<0.05$ vs diabetic group using log values adjusted for baseline levels.

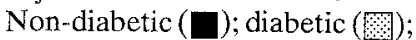
diabetic + tolrestat $(\square)$ 


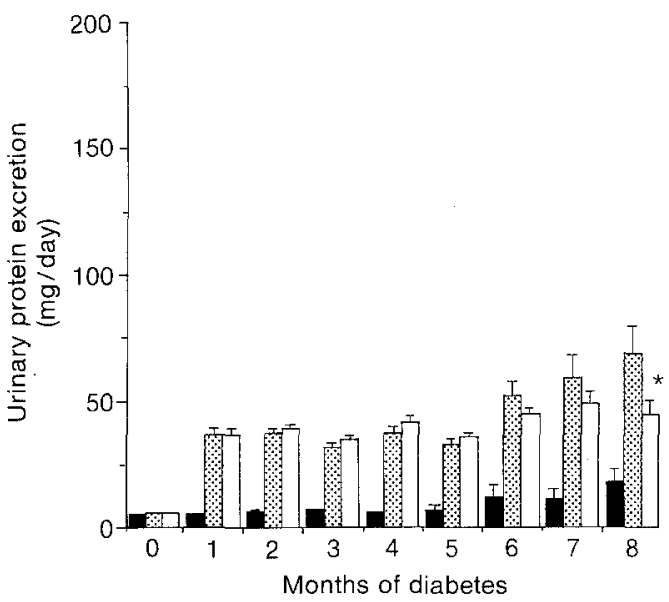

\section{Retinal basement membrane}

The eyes of a randomly chosen sample of rats from each experimental group ( $n=6$ per group) were used to assess changes in retinal capillary basement membrane thickness. Since there was an insignificant difference in basement membrane thickness between the rats of the low and high UAE groups the data of the rats in both groups were pooled. Eight months of hyperglycaemia induced a substantial ( $49 \%$ ) increase over that of age-matched controls in the thickness of the basement membranes of retinal capillaries from the outer plexiform layer (Fig. 3). Intervening treatment of the diabetic rats with tolrestat for the last 6 months of diabetes, significantly inhibited the basement membrane thickening.

Not only were the basement membranes thicker (Fig.4) in the diabetic as compared to the non-diabetic rats, but they also contained more fibrous collagen of the banded type and more clear vacuoles and dense inclusions. The basement membranes in the retinal capillaries of the outer plexiform layer appeared normal, in both

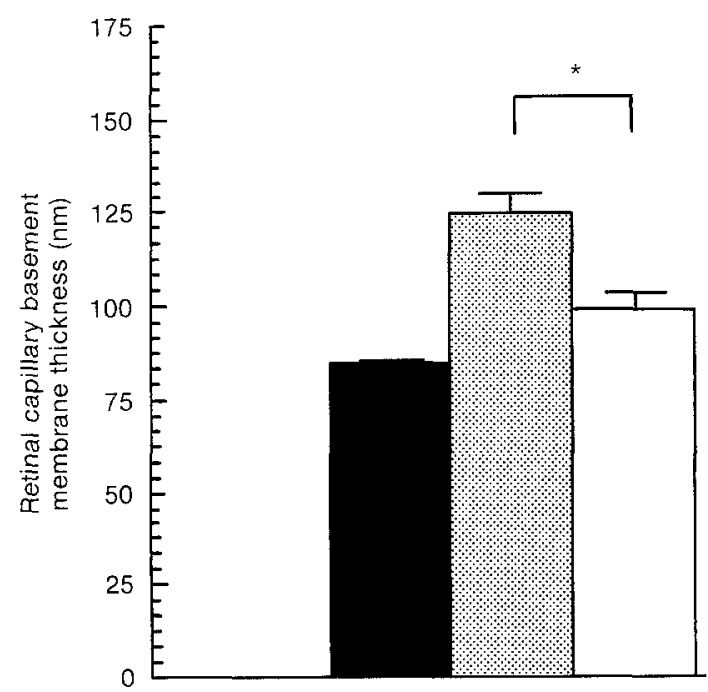

Fig. 3. Effect of intervening tolrestat treatment (months 3-8) on retinal capillary basement membrane thickness in 8-month diabetic rats. ${ }^{*} p<0.05$ vs diabetic group. $n=6,12$ and 12 for non-diabetic

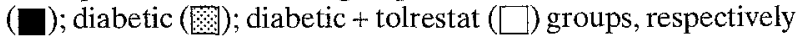

average thickness and in structural content, in the tolrestat-treated rats.

\section{Discussion}

Our previous study [5] demonstrated that diabetes-induced elevations of UAE could essentially be prevented by administration of tolrestat to rats during the entire period of hyperglycaemia. Using a variety of aldose reductase inhibitors (e.g., tolrestat, sorbinil and statil), many other researchers have confirmed this finding [20-22]. It should be noted, however, that there have been a few reports in which, for reasons that are not apparent, conflicting results have been obtained $[23,24]$. There is substantial evidence that the elevation of UAE in diabetic rats is due, at least in part, to the increased flux of glucose through the polyol pathway [25].

In clinical trials, the efficacy of an aldose reductase inhibitor will be assessed initially only after patients exhibit a symptom of diabetic nephropathy, such as albuminuria. Vigilant control of hyperglycaemia in diabetic patients and rats can further reduce increases in existing albuminuria [15-17]. To better approximate clinical trials, it was essential to evaluate the ability of an aldose reductase inhibitor, such as tolrestat, to retard further progression of established albuminuria in diabetic rats.

The ability of tolrestat to slow the progressive worsening of albuminuria was evident in the low UAE group after approximately 3 months of drug treatment and was statistically significant after 6 months of treatment (i.e., at month 8). Within the limited period that the diabetic rats were treated and evaluated, there was no evidence that tolrestat reversed the albuminuria, only that it retarded further progression. A major observation of this study is the dramatic difference in the apparent efficacy of tolrestat when administered in prevention rather than intervention treatment regimens (i. e., comparison of previous data [5] to present data). Although albuminuria has been suggested to be one of the initial symptoms of diabetic nephropathy, substantial and irreversible renal damage may already exist at this early stage $[26,27]$. If irreversible pathologies are present, then drug therapy could be completely successful only if it was initiated prior to the advent 

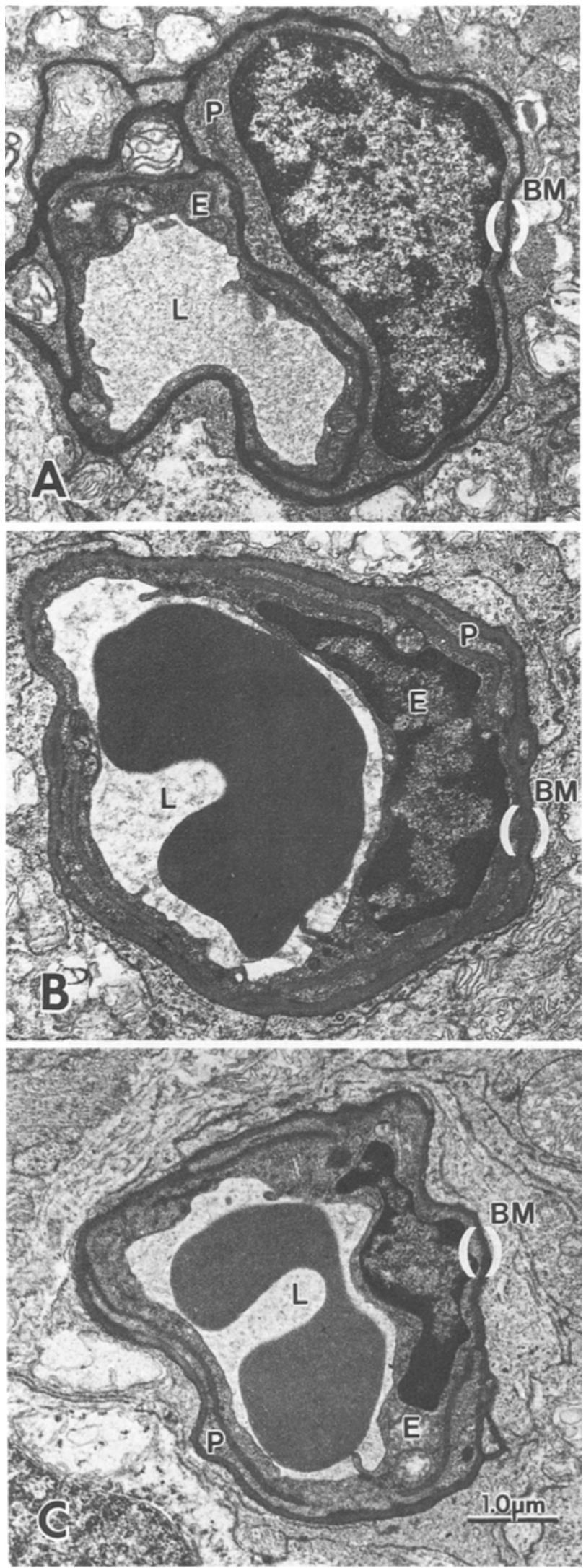

Fig. 4A-C. Representative transections of retinal capillaries from the outer plexiform layer (deep capillary bed) of non-diabetic (A); diabetic (B); and diabetic + tolrestat $(\mathbf{C})$ rats showing the basement membrane (BM and ( )); pericytes (P), endothelial cells $(E)$, and lumen (L) of each (x 14,000) of albuminuria, or at least as early as possible, and only if the treatment period was sufficiently long to allow significant repair of disease damage. Consistent with this premise, tolrestat had greater efficacy in the group of diabetic rats having the lowest UAE. However, additional factors are clearly involved since the urinary excretion of total protein by rats of both the high and low UAE groups was reduced by tolrestat treatment. Additional experiments, in which treatment is initiated at various times, are needed to assess whether the efficacy of tolrestat is more dependent upon the severity of albuminuria or the duration of hyperglycaemia.

Some non-diabetic rats exhibit high UAE rates, which can be comparable to the levels of diabetic rats $[5,28]$. This observation is consistent with the premise that albuminuria in rats is not due entirely to hyperglycaemia. In fact, we previously found that the UAE rate in Zucker (fa/fa) rats was dependent upon age and obesity and independent of blood glucose levels [29]. Other researchers have demonstrated that the albuminuria, which occurs in obese Zucker rats, can be reduced by treatment with lipidlowering agents [30]. Consistent with these reports, we observed that the UAE rates of diabetic rats were significantly correlated with their plasma triglyceride levels after 8 months of diabetes. Whether or not the treatment of either diabetic rats or patients with an antihyperlipidaemic agent is able to reduce the progression of albuminuria is not yet known. Interestingly, a correlation between the incidence rate of albuminuria and hypertriglyceridaemia of diabetic patients has recently been observed [31]. Furthermore, an increase in lipid levels in intestinal microvasculature and lymphatics during lipid absorption was associated with enhanced microvascular permeability to proteins [32]. Determination of the significance of these relationships awaits further experimentation.

An increase in the activation of aldose reductase has also been implicated in the basement membrane thickening, which occurs in the galactosaemic rat model of diabetic complications $[12,13]$. In diabetic rats, retinal capillary basement membrane thickening has been well documented after 12 months diabetes-duration [33], and has been reported to occur as early as 2-4 months after onset [34-36]. However, only a few studies have provided data suggesting a possible beneficial effect of aldose reductase inhibitors [14, 35-37]. The present study further documents a significant thickening of the capillary basement membranes in the retinal capillaries of the outer plexiform layer (deep capillary bed) and demonstrates that intervention with tolrestat after 2 months of established diabetes inhibited the thickening. Studies involving additional sampling times are needed to determine if this inhibition of thickening merely represents halting at an early stage of thickening or a reversal of the thickening process. Interestingly, in a recent publication Chakrabarti and Sima [14] found a different aldose reductase inhibitor, statil, to also affect the basement membrane thickening of retinal capillaries of the outer plexiform layer, but not those of the superficial capillary bed. While in this study we have not investigated the possible effects of tolrestat on the retinal basement membranes of the superficial ca- 
pillary bed, in previous experiments tolrestat was effective in both capillary beds of galactose-fed rats [38].

In conclusion, intervention therapy of STZ-diabetic rats with the aldose reductase inhibitor, tolrestat, significantly inhibited the thickening of retinal capillary basement membranes and the progression of albuminuria in the diabetic rats having initially low rates of UAE. The findings from this study, and others [18, 39-41], suggest that early treatment of diabetic patients with aldose reductase inhibitors may delay or possibly prevent fundamental complications associated with diabetic neuropathy, retinopathy, and nephropathy.

Acknowledgements. The authors wish to thank Dr. C. Kupfer, Director of the National Eye Institute, NIH for his continued encouragement, and Ms. A. Groome, Ms. E. Bynum, and Mr. J. Hackett of the $\mathrm{NIH}$, and multiple members of the Endocrinology Department, Wyeth-Ayerst Research, particularly Ms. T. Tosi, Mr. D. Sullivan, Ms. S. Morris, Mr. M. Basso, Mr. M.Houlihan and Ms. L. Carl, for excellent technical assistance. We would also like to thank Ms. P.Carabelli for her skilful secretarial assistance.

\section{References}

1. Viberti GC, Walker JD (1988) Diabetic nephropathy: etiology and prevention. Diab Metab Rev 4: 147-162

2. Mogensen CE, Christensen CK (1984) Predicting diabetic nephropathy in insulin-dependent patients. N Engl J Med 311: 8993

3. Mauer SM, Brown DM, Matas AJ, Steffes MW (1978) Effects of pancreatic islet transplantation on the increased urinary excretion rates in intact and uninephrectomized rats with diabetes mellitus. Diabetes 27: 959-964

4. Rasch R, Mogensen CE (1980) Urinary excretion of albumin and total protein in normal and streptozotocin diabetic rats. Acta Endocrinol 95: 376-381

5. McCaleb ML, Sredy I, Millen J, Ackerman DM, Dvornik D (1988) Prevention of urinary albumin excretion in 6 month streptozocin-diabetic rats with the aldose reductase inhibitor tolrestat. J Diabetic Comp 2: 16-18

6. Report of the National Commission on Diabetes to the Congress of the United States (1976) Vol. 1, The long-range plan to combat diabetes. Bethesda, MD: Department of Health, Education, and Welfare (DHEW publication no. (NIH) 76-1018)

7. Ashton N (1974) Vascular basement membrane changes in diabetic retinopathy. Br J Ophthalmol 58:344-366

8. Bloodworth Jr JMB, Engerman RL, Camerini-Davalos RA, Powers KL (1970) Variations in capillary basement membrane width produced by aging and diabetes mellitus. Adv Metab Disord 1 [Suppl]: 279-295

9. Williamson JR, Kilo C (1977) Current status of capillary basement-membrane disease in diabetes mellitus. Diabetes 26:65-73

10. Nagata M, Katz ML, Robison Jr WG (1986) Age-related thickening of retinal capillary basement membranes. Invest Ophthalmol Vis Sci 27: 437-440

11. Robison Jr WG (1988) Prevention of diabetes-related retinal microangiopathy with aldose reductase inhibitors. In: CameriniDavalos RA, Cole HS (eds) Prediabetes, advances in experimental medicine and biology, Vol 246. Plenum Publishing, New York, pp 365-372

12. Robison Jr WG, Kador PF, Kinoshita JH (1983) Retinal capillaries: Basement membrane thickening by galactosemia prevented with an aldose reductase inhibitor. Science 221: 11771179

13. Frank RN, Keirn RJ, Kennedy A, Frank KW (1983) Galactose-induced retinal capillary basement membrane thicken- ing: prevention by sorbinil. Invest Ophthalmol Vis Sci 24: 15191524

14. Chakrabarti S, Sima AAF (1989) Effect of aldose reductase inhibition and insulin treatment on retinal capillary basement membrane thickening in BB rats. Diabetes 38: 1181-1186

15. Kroc Collaborative Study Group (1984) Blood glucose control and the evaluation of diabetic retinopathy and albuminuria. $\mathrm{N}$ Eng J Med 311: 365-372

16. Dahl-Jorgensen K, Hanssen KF, Kierulf P, Bjoro T, Sandrik L, Aagenaes O (1988) Reduction of urinary albumin excretion after 4 years of continuous subcutaneous insulin infusion in insulin-dependent diabetes mellitus, The Oslo Study. Acta Endocrinol 117: 19-25

17. Cohen AJ, McGill PD, Rossetti RG, Gugerski DL, Like AA (1987) Glomerulopathy in spontaneously diabetic rat. Impact of glycemic control. Diabetes 36: 944-951

18. Robison Jr WG, Kador PF, Akagi Y, Kinoshita JH, Gonzalez R, Dvornik D (1986) Prevention of basement membrane thickening in retinal capillaries by a novel inhibitor of aldose reductase, tolrestat. Diabetes 35: 295-299

19. Guerrant GO, Moss CW (1984) Determination of monosaccharides as aldonitrile, o-methyloxime, alditol, and cyclitol acetate derivatives by gas chromatography. Anal Chem 56: 633-638

20. Beyer-Mears A, Cruz E, Edelist T, Varagiannis E (1986) Diminished proteinuria in diabetes mellitus by sorbinil, an aldose reductase inhibitor. Pharmacol 32: 52-60

21. Kawazu S, Watanabe T, Hokama A et al. (1987) Diabetic nephropathy and sorbitol pathway in BB/W rat. In: Sakamoto N, Alberti KGMM, Hotta N (eds) Recent trends in management of diabetes mellitus. Elsevier, Amsterdam, pp 595-597

22. Tilton RG, Chang K, Pugliese G et al. (1989) Prevention of hemodynamic and vascular albumin filtration changes in diabetic rats by aldose reductase inhibitors. Diabetes 38: 12581270

23. Daniels BS, Hostetter TH (1989) Aldose reductase inhibition and glomerular abnormalities in diabetic rats. Diabetes 38: 981 986

24. Mauer SM, Steffes MW, Azar S, Brown DM (1989) Effects of sorbinil on glomerular structure and function in long-termdiabetic rats. Diabetes 38: 839-846

25. Stribling D, Armstrong FM, Harrison HE (1989) Aldose reductase in the etiology of diabetic complications: 2. Nephropathy. J Diab Comp 3: 70--76

26. Mogensen CE (1987) Early diabetic renal involvement and nephropathy. In: Alberti KGMM, Krall LP (eds) The diabetes annual, 13. Elsevier, Amsterdam, pp 306-324

27. Goldfarb S, Ziyadeh FN (1989) Glomerular lesions and microalbuminuria in diabetes. N Engl J Med 321: 759

28. Goldstein RS, Tarloff JB, Hook JB (1988) Age-related nephropathy in laboratory rats. FASEB J 2: 2241-2251

29. McCaleb ML, Sredy J (1989) Metabolic abnormalities of the hyperglycemic obese Zucker rat. J Cell Biochem [Suppl. 13E] 238

30. Kasiske BL, O'Donnell MP, Cleary MP, Keane WF (1988) Treatment of hyperlipidemia reduces glomerular injury in obese Zucker rats. Kid Int 33: 667-672

31. Niskanen L, Uusitupa M, Sarlund H et al. (1990) Microalbuminuria predicts the development of serum lipoprotein abnormalities favouring atherogenesis in newly diagnosed Type 2 (non-insulin-dependent) diabetic patients. Diabetologia 33: $237-243$

32. Granger DN, Korthuis RJ, Kvietys PR, Tso P (1988) Intestinal microvascular fluid exchange during lipid absorption. FASEB J 2: A741

33. Fischer F, Gaertner $J$ (1983) Morphometic analysis of basal laminae in rats with long-term streptozotocin diabetes. II. Retinal capillaries. Exp Eye Res 37: 55-64

34. Waber S, Meister V, Rossi GL, Mordasini R-C, Riesen WF (1981) Studies on retinal microangiopathy and coronary microangiopathy in rats with streptozotocin-induced diabetes. Virch Arch [Cell Pathol] 37: 1-10 
35. Kojima K, Matsubara H, Harada T et al. (1985) Effects of aldose reductase inhibitor on retinal microangiopathy in streptozocin-diabetic rats. Jpn J Ophthalmol 29: 99-109

36. Chandler ML, Shannon WA, DeSantis L (1984) Prevention of retinal capillary basement membrane thickening in diabetic rats by aldose reductase inhibitors. Invest Ophthamol Vis Sci 25 [Suppl.]: 159

37. Kinoshita JH, Nishimura C (1988) The involvement of aldose reductase in diabetic complications. Diab Metab Rev 4:323-337

38. Kinoshita JH, Datiles MB, Kador PF, Robison Jr WG (1990) Aldose reductase and diabetic eye complications. In: Rifkin $\mathrm{H}$, Porte Jr D (eds) Ellenberg and Rifkin's diabetes mellitus, theory and practice, 4 th edn. Elsevier, New York, pp 264-278

39. Kador PF, Akagi Y, Takahaski Y, Ikebe H, Wyman M, Kinoshita JH (1990) Prevention of retinal vessel changes associated with diabetic retinopathy in galactose-fed dogs by aldose reductase inhibitors. Arch Ophthalmol 108: 1301-1309
40. Robison Jr WG, Nagata M, Laver N, Hohman TC, Kinoshita JH (1989) Diabetic-like retinopathy in rats prevented with an aldose reductase inhibitor. Invest Ophthalmol Vis Sci 30: 22852292

41. Boulton AJM, Levin S, Comstock J (1990) A multicentre trial of the aldose reductase inhibitor, tolrestat, in patients with symptomatic diabetic neuropathy. Diabetologia 33: 431-437

Received: 8 March 1991

and in revised form: 17 June 1991

Dr. M.L. McCaleb

Wyeth-Ayerst Research

CN 8000

Princeton, New Jersey 08543

USA 